\title{
Scanning electron microscopy of the spores of Gyromitra subg. Gyromitra and subg. Discina (Pezizales)
}

\author{
HARRI HARMAJA
}

\begin{abstract}
HARMAJA, H. 1976: Scanning electron microscopy of the spores of Gyromitra subg. Gyromitra and subg. Discina (Pezizales). - Karstenia 16:6-9.

The spore surface was studied with the SEM in three species of Gyromitra Fr. subg. Gyromitra, viz. G. ambigua (Karst.) Harmaja, G. esculenta (Pers.) Fr. and G. infula (Fr.) Quél., and in two species of Gyromitra subg. Discina (Fr.) Harmaja, viz. G. gigas (Krombh.) Quél. and G. montana Harmaja. G. ambigua and $G$. esculenta have not been examined with the SEM before.

The spores were found to be ornamented in all the species studied, having a fairly regular pattern with ridges running in different directions. The relief of the ornamentation varies with the species, being lowest in G. esculenta and highest in G. gigas. No differences in kind exist between the spore surfaces of the two subgenera, and the difference in degree is almost negligible between the ornamentation with the highest relief in subg. Gyromitra (in G. ambigua) and that with the lowest relief in subg. Discina (in G. montana). The difference between 'smooth' and rough spores can no longer be used as the basic generic character. Thus the present results justify the author's earlier proposal that the genus Discina (Fr.) Fr. sensu Eckblad (i.e., including Maublancomyces Herter and Neogyromitra Imai) should be merged in Gyromitra.
\end{abstract}

Harri Harmaja, Botanical Museum, University of Helsinki, SF-00170 Helsinki 17, Finland

\section{Materials and methods}

Six specimens of Gyromitra Fr., nom. conserv. (sensu Harmaja 1973), listed below, representing both subgenera of the genus, were studied:

Gyromitra ambigua (Karst.) Harmaja. - Finland, Uusimaa, Helsinki, Länsisalmi, 8. IX. 1951, R. Tuomikoski; det. H. Harmaja (H). - Finland, Kemin Lappi, Muonio, church village, 17. IX. 1972, H. Harmaja (H).

G. esculenta (Pers.) Fr. - Finland, Etelä-Savo, Pertunmaa, Hölttä, 13. VI. 1970, P. Isoviita (H).

G. gigas (Krombh.) Quél. - Finland, Varsinais-Suomi, Lohja rural district, Torhola, 6. VI. 1972, H. Harmaja (H).

G. infula (Fr.) Quél. - Finland, Kemin Lappi, Kittilä, Pallas-Ounas National Park, 10. IX. 1972, H. Harmaja (H).

G. montana Harmaja. - U.S.A., Wyoming, Teton Co., 24. VI. 1967, K. B. McKnight \& J. B. McKnight; det. H. Harmaja, originally det. as $G$. gigas by K. H. McKnight 10351 (H: holotype).

An air-dry piece of hymenium from each of the specimens was coated directly with gold evaporated from a tungsten filament. Scanning electron micrographs were then taken of the preparations with a JSM-U3 scanning electron microscope at the Department of Electron Microscopy of the University of Helsinki.

\section{Results}

1. The spore surface of all the species studied is uneven. 2. The unevenness is of the same kind in all the species, consisting of fairly regular ornamentation produced by elevated ridges running in different directions, locally and infrequently (but frequently in G. gigas) tending to form an indistinct reticulate pattern.

3. The relief of the ornamentation is different in all the species. The sequence of the species when arranged in order of increasing relief is as follows: G. esculenta (Figs. 1-2), G. infula (Fig. 3), G. ambigua (Figs. 4-6), G. montana (Figs. 7-8), G. gigas (Fig. 9).

\section{Discussion}

The genera Discina (Fr.) Fr., Maublancomyces Herter, Neogyromitra Imai and Pseudorbizina Jač. were merged by me in Gyromitra (Harmaja 1969). Later the genus Gyromitra was once more amended, by the removal of two species considered to form the valid genus Pseudorbizina (Harmaja 1973). In the last-named paper the genus was also divided into two subgenera, Gyromitra and Discina (Fr.) Harmaja. In Harmaja 1976 some additional notes were given. Especially in my 1973 paper I presented detailed criticism 
against the arguments of those who wanted to separate Discina sensu Eckblad (1968) or both Discina and Neogyromitra from Gyromitra although at that time no SEM studies on species of Gyromitra s. str. had been performed. I considered that their arguments were based on differences in degree not in kind and that the characters in question were quite correctly treated as infrageneric elsewhere in the order (e.g. in Helvella St-Amans and Peziza St-Amans). Dissing (1972) even claimed that the supposedly smooth cyanophilic perisporial sheath surrounding the spores of Gyromitra s. str. and the 'apiculi' of the spores of Discina and Neogyromitra have not been proved homologous. However, everything that at present is known about these structures in fact indicates that the cyanophilic matter surrounding the spores in all three species groups (genera according to Dissing's taxonomy) is homologous. Firstly, the cyanophilic matter in Discina and Neogyromitra spores is not restricted to the 'apiculi' and 'ornamentation' as Dissing erroneously believes but the spores in these species groups, too, are surrounded by a continuous strongly cyanophilic sheath, though this usually (but not always!) has more pronounced swellings ('apiculi') at the spore ends than in Gyromitra s. str. as well as \pm distinct ornamentations. Le Gal (1947) was acquainted with, and depicted, this cyanophilic sheath of Discina and Neogyromitra as early as in the 1940s. The transmission electron micrographs of the spores of Neogyromitra 'caroliniana' $(=$ G. fastigiata (Krombh.) Rehm) and N. gigas in Moberg (1970) and those of $D$. perlata in Meléndez-Howell (1976) also show clearly a continuous outer sheath in the spores, the 'apiculi' being nothing but parts of this sheath. Secondly, this sheath, which according to my studies is also at least slightly swollen at the spore ends in all the species of Gyromitra s. str., develops in an identical manner in all three species groups: my observations on various species have revealed that it first appears as two separate cyanophilic caps at the ends of the young spores, which caps gradually grow towards each other till they merge to form a continuous sheath; this was also observed already by Le Gal (1947) as concerns Discina and Neogyromitra. Thirdly, in all three 'genera' these sheaths swell in $\mathrm{KOH}$ (cf. also McKnight 1968). As far as I know, no one has provided any evidence supporting the view that the 'smooth' cyanophilic sheath of Gyromitra s. str. is not homologous with the more or less distinctly ornamented one of those two 'genera' (nor has any author claimed that the smooth cyanophilic sheaths of some species of Helvella and Peziza are not homologous with the ornamented ones of other species of these genera; in Helvella the ornamentation may even be inconstant within the species).

The separation of Gyromitra s. str. and Discina sensu Eckblad is almost exclusively based on a supposed difference in the kind of spore surface (the purely quantitative difference in the number of oil drops is also emphasized): it is consistently said to be completely smooth under the light microscope in the former but more or less distinctly ornamented in the latter. All facts considered, even if this were true, it would appear unnatural to keep the genera apart (Harmaja 1969, 1973, 1974). However, in 1973 I reported observing - under the light microscope occasional ornamented spores in two species of Gyromitra s. str., namely G. ambigua and G. tasmanica Berk. \& Cooke. It seemed possible that the spores of the former might possess extremely faint markings even as a rule, but the resolution power of the light microscope did not allow any definite conclusion. The results of the present study solve this most important problem and confirm that ornamentation is regularly present in the spores of not only $G$. ambigua but also $G$. infula and even $G$. esculenta, the type of Gyromitra. The markings are of the same kind in Gyromitra s. str. and Discina s. lato (= sensu Eckblad 1968). In both groups their relief varies with species, and the ornamentation with the greatest relief in the former (that of $G$. ambigua) approaches the ornamentation with the smallest relief in the latter (such as that of G. montana examined in the present study). McKnight (1969 and 1971) even claimed that a part of the spores of D. apiculatula McKnight, D. olympiana Kanouse and G. montana (as G. 'gigas') would be smooth (however, my own observations revealed that all the mature spores are ornamented in all these species, too, the markings being best discernible when stained with cotton blue). The spore ornamentation is admittedly more prominent in Discina, as had already been observed with the light microscope studies, but it is mere chance that it is the markings of the biguttulate species (i.e. Gyromitra s. str.) that happen to be beyond the limit of resolution of the light microscope. The recognition of the Discina group as a subgenus of Gyromitra (Harmaja 1973) will not be affected by the present results. It is hoped that the results of the present study can be considered final justification for merging the genera Gyromitra and Discina (incl. Neogyromitra).

Species of the subgenus Discina have been examined with the SEM also before, and the spore micrographs published (Dissing 1972, Dissing \& Raitviir 1974, McKnight \& Batra 1974, Meléndez-Howell 1976) are in line with the present results. McKnight \& Batra (1974) also examined the spore surface of a representative of subg. Gyromitra, G. infula, and likewise complete concordance with their results and mine exists in the respect of that species.

The SE micrographs published so far appear further to confirm my supposition (Harmaja 1973) that the much discussed ornamentation of the spore surface of the species of the Discina and Neogyromitra groups is nothing but folds of different degree in the rather soft, continuous and most probably homogeneous sheath (the perisporium, or the secondary wall) which surrounds the spore. 

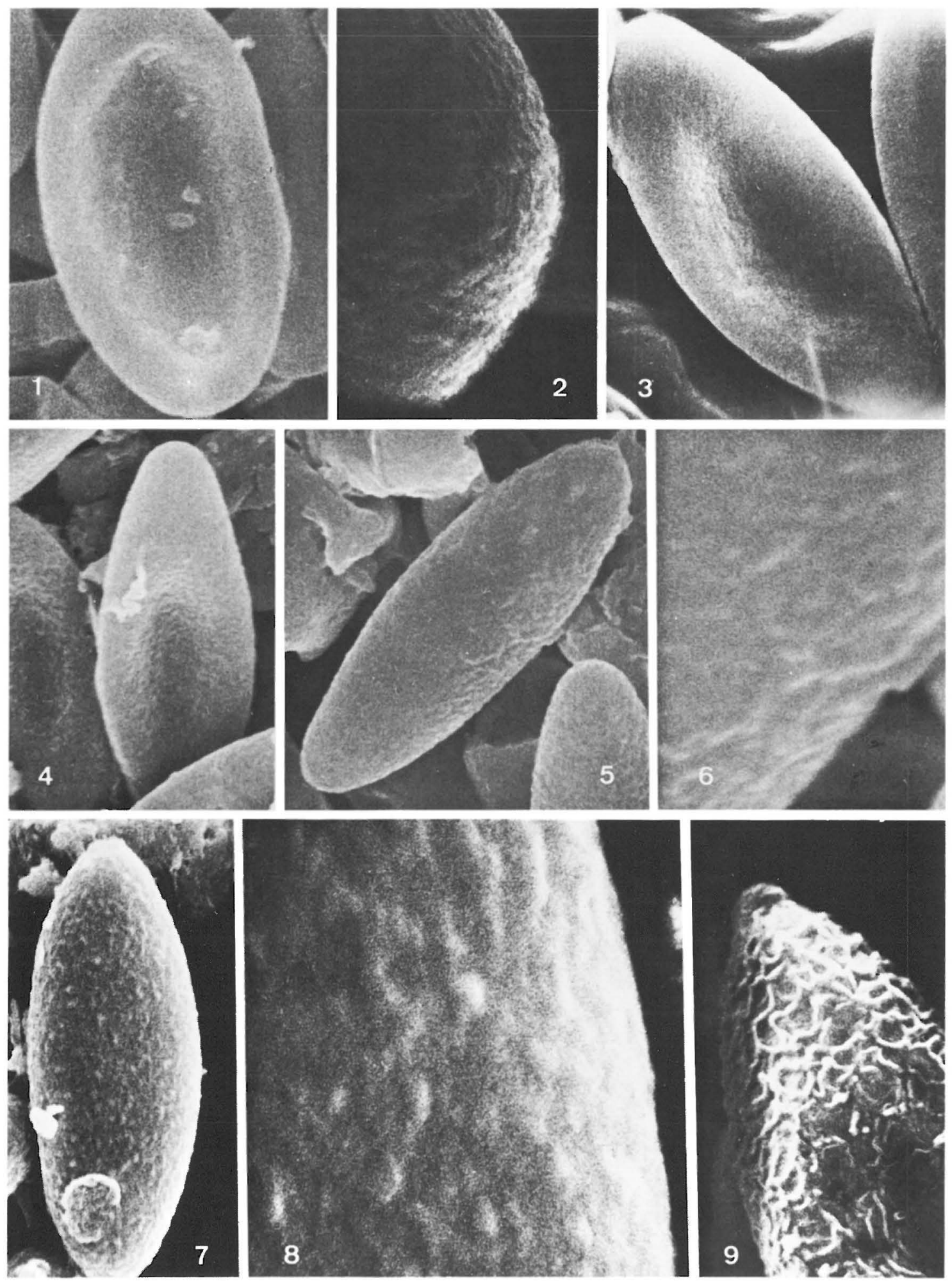
Acknowledgements. Dr. Tuomo Niemelä, Mr. Mauri Korhonen, and Miss Sirkka-Liisa Seppänen were of the greatest help in the technical part of the study, for which I am much indebted to them all.

\section{References}

Dissing, H. 1972: Specific and generic delimitation in the Helvellaceae. - Persoonia 6: 425-432 +23 .

Dissing, H. \& Raitviir, A. 1974: Discomycetes of Middle Asia. III. Otideaceae, Helvellaceae, Morchellaceae and Sarcoscyphaceae from the Tien-Shan mountains. - Eesti NSV Tead. Akad. Toim. 23 (Biol.): 104-111 + 4-12.

Eckblad, F.-E. 1968: The genera of the operculate Discomycetes. A re-evaluation of their taxonomy, phylogeny and nomenclature. - Nytt Mag. Bot. 15: 1-191.

Harmaja, H. 1969: A wider and more natural concept of the genus Gyromitra Fr. - Karstenia 9: 9-12.

- "-1973: Amendments of the limits of the genera Gyromitra and Pseudorhizina, with the description of a new species, Gyromitra montana. - Karstenia 13: 48-58.

- " -1974: Observations on the presence of a cyanophilic perispore in the spores of the Pezizales. - Karstenia 14: 119-121. - - 1976: New species and combinations in the genera Gyromitra,
Helvella and Otidea. - Karstenia 15: 29-32.

Le Gal, M. 1947: Recherches sur les ornementations sporales des Discomycètes operculés. - Ann. Sci. Nat. 11 (Bot. 8): 73-297.

McKnight, K. H. 1968: Artifacts on spores of Discineae induced by common reagents. - Mycologia 60: 723-727.

- -1969: A note on Discina. - Mycologia 61: 614-630.

- " 1971: On two species of false morels (Gyromitra) in Utah. Great Basin Nat. 31: 35-47.

McKnight, K. H. \& Batra, L. R. 1974: Scanning electron microscopy in taxonomy of gyromitroid fungi. - Michigan Bot. 13: 51-64.

Meléndez-Howell, L.-M. 1976: Recherches préliminaires sur la germination des spores de Discomycètes. - Rev. Mycol. 40: 117-123.

Moberg, R. 1970: Neogyromitra caroliniana and N. gigas in Fennoscandia. - Friesia 9: 341-343 + 5-6.

\section{Accepted for publication \\ on 29 October 1976}

Figs. 1-9. SE micrographs of the spore surfaces of five species of Gyromitra. -1 : G. esculenta, magnification $\times 3700$ (with this magnification the spores appear practically smooth). $-2: G$. esculenta, $\times 9300 .-3: G$. infula, $\times 3900$ (the spore surface appears almost smooth with this magnification). - 4: G. ambigua, Muonio specimen, x 2900. - 5: G. ambigua, Helsinki specimen, x 2900. - 6: G. ambigua, Helsinki specimen, x 7700. - 7: G. montana, x 2300. - 8: G. montana, x 9300. - 9: G. gigas, x 3900. 